\title{
Inhalation Vapor, Liquid Dosage Form
}

National Cancer Institute

\section{Source}

National Cancer Institute. Inhalation Vapor, Liquid Dosage Form. NCI Thesaurus. Code C149587.

Liquid preparation consisting of a liquid active substance per se, such as an essential oil or a volatile anesthetic, intended for generation of vapor to be inhaled. The vapor may be generated by adding the liquid to hot water or by the use of a vaporizing device. 